\title{
The effects of single-sex versus coeducational physical education on american junior high PE students' physical activity levels and self-competence
}

\author{
Crystal Vargos $^{1}$, Skip M. Williams², Mary L. Henninger ${ }^{2}$, Margaret M. Coleman², Ryan Burns ${ }^{3}$ \\ ${ }^{1}$ Mokena Jr. High School, Mokena, IL, USA; 2 Illinois State University, Normal, IL, USA; ${ }^{3}$ University of Utah, Salt Lake \\ City, UT, USA
}

\begin{abstract}
Study aim: To examine single-sex classes versus coeducational classes in $7^{\text {th }}$ grade PE and the effect the setting had on physical activity (PA) levels and self-competence.

Material and methods: A total of 85 students aged 12-13 years old, enrolled in the $7^{\text {th }}$ grade from one junior high in the Midwestern part of the U.S.A. participated. Classes were randomly assigned as coed or single-sex. The study took place during eight lessons of a basketball unit. Four of the lessons focused on skill and four focused on game play. Average heart rate (HR) levels were recorded through HR monitors. A modified version of the Confidence in Learning Mathematics scale was administered to the students.

Results: A $2 \times 2$ Factorial ANOVA was completed to examine the effect of setting and gender on average HR during gameplay lessons, average HR during skill-based lessons, confidence, usefulness, and appropriateness. Results revealed on average, girls had fewer bpm compared to boys during gameplay. Also, girls in the single-sex setting had, on average, higher HR during gameplay compared to girls in coeducational.

Conclusions: Similarly, to other research, males had higher bpm during game play than females and higher HR's in the singlesex setting than the coed setting. This suggests that during basketball it might be more ideal for females to participate in a single-sex setting to elicit more activity.
\end{abstract}

Key words: Gender appropriateness - Title IX - Confidence - Heart Rate Monitors - Class environment

\section{Introduction}

According to the World Health Organization (WHO), worldwide obesity has nearly tripled since 1975 [29]. In 2016 , WHO reported that $39 \%$ of adults over the age of 18 were overweight and $13 \%$ were obese and 340 million youth were overweight [29]. Specifically, in the United States (U.S.) the Centers for Disease Control (CDC) reported, more than one-third of American adults are obese [3]. Additionally, obesity is responsible for $18 \%$ of all deaths in the United States [3]. Obesity affects people socially, culturally, genetically, metabolically, behaviorally, and even psychologically [3]. Obesity causes diabetes, hypertension, arteriosclerosis, heart attacks, strokes, cancer, difficulty in breathing, and worsened arthritis [3].
Partaking in Physical Activity (PA) is one way to prevent obesity, especially in adolescents [3]. More specifically, participating in physical education (PE) in school is an important way for children to be physically active [12].

In 1972, Title IX was enacted [25]. In the United States Title IX was a civil rights law that protects individuals from discrimination based on sex in education settings. An implication of title IX was that schools provide equal opportunities in all PE activities, regardless of gender [25]. PE classes then became coed. In the U.S. it is only appropriate to separate PE classes by gender during contact sports such as hockey, football and wrestling. In many cases, coed classes have had a negative effect on a portion of the participation levels in PE [17]. There are many different factors that influence the participation level in PE other than gender itself [17]. For instance, social constructions 
of gender, gender stereotypes, support systems and social influences, classroom environment, the instructor, and the competitive design of PE classes all have influences on each gender in PE class [17]. Feelings of embarrassment, lack of confidence and self-efficacy, body image concerns, disinterest activities, and dominance of males in PE are also reasons why females, specifically, may dislike participating in PA in PE class [17].

In a survey conducted by Cockburn [2], nearly onethird of $9^{\text {th }}$ grade females that were participants in the study disliked being in the same PE class as males. Additionally, close to one quarter of the girls that took the survey said that they would enjoy a class with only females more than a class with mixed genders. Furthermore, a study done by Lirgg [14] found that at the middle school level, both males and females preferred single-sex PE classes. In another study, game involvement during a basketball unit was examined. Coeducational groups were compared with single-sex groups and it turned out that the students in the single-sex group had more game involvement than the students who were grouped with males and females [20]. This study displayed the effect of classroom environment and the importance of the quality of a PE program.

According to the National Association of Sport and PE (NASPE), a high-quality PE program includes an opportunity to learn, meaningful content, and appropriate instruction [18]. In order to provide a quality program, teachers must choose what is best for their students, such as the content to be taught, length of the lesson, and whether or not to teach the unit in a coeducational manner [20]. Some units may work better in a coeducational setting, while others may be more fitting for a single-sex setting. Research shows that class type has a significant influence on students' perceived competence, motivation, and performance [5]. Additionally, Rowe [21] found that students in single-sex classes had an increase in confidence, compared with students in coeducational settings. This study will help further the research done on the effects of the PE environment on males and females. The purpose of this study was to examine single-sex classes versus coeducational classes in $7^{\text {th }}$ grade PE and the effect it had on PA level and perceived self-competence. A secondary purpose was to examine differences in PA levels between males and females in PE.

\section{Material and methods}

\section{Participants and setting}

This study was conducted at a junior high in the MidWestern United States (U.S.). The school was $88.5 \%$ White. Four classes of $7^{\text {th }}$ grade students $(n=40$ females and $n=45$ males) for a total of 85 students participated in this study. Two certified PE teachers taught all lessons in this study. The combined teaching experience between the two teachers was 11 years. The study took place in one of the large gymnasiums at the school. Two of the four classes had a single-sex environment while the other two were coeducational. Both groups received the same basketball lessons. Basketball was chosen for this study because of the popularity of the team sports that are commonly taught in PE. In addition, basketball is considered a gender-neutral sport. Playing invasion games, such as basketball, in gender-specific groups can potentially be a beneficial method that teachers can use in order to improve self-competence in students, especially females [22].

\section{Instrumentation}

Students completed a demographic in a classroom setting. Questions regarding gender, age and feelings toward each PE environment were asked. All students filled out the demographic survey, but only those with assent and parental consent were analyzed for the study.

A survey was given to all the students in the class. Students that had given assent and parental consent were a part of the study. The survey given was a modified version of the Confidence in Learning Mathematics scale, Math as a Male Domain scale, and Usefulness of Mathematics scale [6], where basketball was be substituted for mathematics. Questions focusing on confidence, usefulness, and gender-appropriateness were given in the survey and had choices numbered 1-5. 1 meaning strongly disagree, 2 meaning disagree, 3 meaning not sure, 4 meaning agree, and 5 meaning strongly agree. This survey was given a total of two times. The students took it one day before the basketball unit started and one day after it was over in a classroom. The survey was given by the instructor.

The heart rate monitors that were used for this study were the Heart Zones Blink Armband. The monitors consisted of a programmable armband that had one button on it. The armband assessed heart rate, calories burned, distance, pace, and overall intensity level. The armband also used optical sensors and provided three different colored lights to represent various heart rate zones. They were waterproof, rechargeable, and easy for students to manage [10]. At the end of the lesson, the data-collecting program Blink Armbands generated a report of the data. The report provided the average beats per minutes (bpm) per lesson.

\section{Data collection procedures}

Approval by the school administration and the IRB was obtained prior to the start of this study. The students in the class were each given a consent form to bring home to parents. All students turned in the consent form allowing them to participate in the study. A message was posted in the grading system as a brief overview of what the study entailed and reminded the parents to fill out the consent form. A review of the study was also given to the 
students in a verbal manner. Students were given a questionnaire regarding demographic information and the selfcompetence survey in a classroom from their respective teacher one day before the unit began and one day after it was over.

Students had previous experience with the Heart Zones Blink Armbands. However, before the study, students had a quick overview of the proper way to utilize the armbands. The students put on the heart rate monitors right after they got dressed and then proceeded to their assigned "squad spots". The students already knew which heart rate monitor to utilize, as they were assigned a number. The students put the heart rate monitors back in their correct space after the lesson was completed. The instructor ensured that each armband was working properly, and students were instructed to wear them on the forearm. Lessons were taught to the class and PA level was monitored through the armbands. Average heart rate levels were documented by the Heart Zones software.

The data were collected over a series of eight lessons during a two week time period. Four of the eight were skill days while the other four were game play days. The students in the single-sex setting were in the same gym as the males, but there was no interaction between the two genders. Both teachers gave the same lesson to each group. In the coeducational setting, the students were mixed and interaction with the opposite gender took place. Throughout the unit, lessons started out with a quick overview of what to expect. They were told that the lesson would start with a five-minute warmup, which would be based on cardiovascular endurance. During the skill and game play days, lessons were designed to be cardiovascular endurance based. The skill days consisted of the students practicing the skills for a short while, followed by a modified game that focused on the skill being learned at a relatively high intensity. Game play days consisted of the participants playing five on five games in a basketball tournament. At the end of each lesson, students reported their average heart rates using the Blink Armbands.

\section{Data analysis}

Descriptive statistics for the total sample and separated by sex were completed and are presented as means $\pm \mathrm{SD}$. Mean total/bpm for each individual were computed, as were mean scores computed for the subscales (confidence, usefulness, and gender-appropriateness) of the perceived self-competence survey and demographic information (see Table 1).

Statistical analysis was completed using STATA v14 [23]. A $2 \times 2$ factorial ANOVA was completed to examine the effect of setting (2 levels: co-ed, same sex) and gender (2 levels: male, female) on average heart rate during gameplay lessons, average heart rate during skill-based lessons, confidence, usefulness, and appropriateness). Main effects and the setting $\mathrm{x}$ gender interactions were examined within each ANOVA model. For the psychometric variables, the "pre-test" measurements were used as covariates and the "post-test" measurements were the outcome variables. The a priori alpha level was set up at $\alpha=0.05$.

\section{Results}

Descriptive statistics for all variables can be found in Table 1 . There was a statistically significant main effect of gender on heart rate during gameplay $(p=0.024)$. On average, girls had 9.3 fewer bpm (mean difference $=9.3 \mathrm{bpm}$; $95 \% \mathrm{CI}=-17.3 \mathrm{bpm},-1.3 \mathrm{bpm}$ ) compared to boys during gameplay. There was also a statistically significant setting $\mathrm{x}$ gender interaction where girls in the same-gender setting had, on average, $12.3 \mathrm{bpm}$ higher heart rates during gameplay compared to girls in coeducational classes (mean difference $=12.3 \mathrm{bpm}, 95 \% \mathrm{CI}=1.8 \mathrm{bpm}, 22.8$

Table 1. Average scores for HR skill lessons, HR game lessons, HR all lessons and pre-and post-confidence, usefulness and gender appropriateness (mean $\pm \mathrm{SD}$ )

\begin{tabular}{lccc}
\hline & Boys & Girls & Total \\
\hline HR skill lessons $[\mathrm{bpm}]$ & $151.87 \pm 8.4$ & $155.9 \pm 11.4$ & $153.75 \pm 10.1$ \\
HR game lessons $[\mathrm{bpm}]$ & $153.7 \pm 9.7$ & $149.8 \pm 13.8$ & $151.86 \pm 11.9$ \\
HR all lessons $[\mathrm{bpm}]$ & $152.8 \pm 7.6$ & $153.0 \pm 12.2$ & $152.92 \pm 9.9$ \\
Pre confidence & $3.34 \pm 0.28$ & $3.19 \pm 0.19$ & $3.27 \pm 0.26$ \\
Pre usefulness & $3.14 \pm 0.25$ & $2.97 \pm 0.18$ & $3.06 \pm 0.24$ \\
Pre gender appropriateness & $3.15 \pm 0.25$ & $3.09 \pm 0.21$ & $3.12 \pm 0.24$ \\
Post confidence & $3.31 \pm 0.27$ & $3.25 \pm 0.25$ & $3.28 \pm 0.26$ \\
Post usefulness & $3.15 \pm 0.29$ & $3.06 \pm 0.20$ & $3.11 \pm 0.26$ \\
Post gender appropriateness & $3.17 \pm 0.28$ & $3.04 \pm 0.25$ & $3.11 \pm 0.27$ \\
\hline
\end{tabular}


Table 2. Average scores for coeducational and same-gender preference questions and self-perception questions (mean \pm SD)

\begin{tabular}{|c|c|c|c|}
\hline & Boys & Girls & Total \\
\hline \multicolumn{4}{|l|}{ Coeducational and same-gender preference questions } \\
\hline 1. I like being in the same class as the opposite gender & $3.8 \pm 0.81$ & $3.92 \pm 0.92$ & $3.87 \pm 0.86$ \\
\hline 2. I would rather be in a PE class with only students of the same gender as me. & $2.42 \pm 0.94$ & $2.25 \pm 1.0$ & $2.34 \pm 0.97$ \\
\hline $\begin{array}{l}\text { 3. I would rather be in a PE class with both males and females than in a PE class } \\
\text { with only people the same gender as me }\end{array}$ & $3.96 \pm 0.85$ & $3.78 \pm 1.1$ & $3.87 \pm 0.96$ \\
\hline \multicolumn{4}{|l|}{ Self-perception questions } \\
\hline 1. I like physical education. & $3.51 \pm 0.55$ & $3.07 \pm 0.66$ & $3.31 \pm 0.64$ \\
\hline 2. I try hard in physical education. & $3.56 \pm 0.55$ & $3.30 \pm 0.56$ & $3.44 \pm 0.57$ \\
\hline 3. I follow rules and behave well in physical education & $3.56 \pm 0.50$ & $3.45 \pm 0.50$ & $3.51 \pm 0.50$ \\
\hline 4. I have good sport skills in physical education. & $3.49 \pm 0.66$ & $3.00 \pm 0.82$ & $3.26 \pm 0.77$ \\
\hline
\end{tabular}

bpm; $\mathrm{p}=0.022$ ). As shown in Figure 1, other follow-up comparisons revealed that girls had higher heart rates during gameplay compared to boys $(\mathrm{p}=0.04)$ in same-gender classes, but boys had higher heart rates during gameplay compared to girls in coeducational classes $(p=0.008)$. There was not a significant relationship found in student preferences of PE setting in the survey with $\mathrm{A}=$ Coeducational setting $B=$ Single-sex setting $(M=1.35, \mathrm{SD}=$ 0.481). Out of the 85 participants, 55 chose the coeducational setting and 30 chose the single-sex setting. There were not any other statistically significant effects that were found on any of the other dependent variables in the study $(\mathrm{p}>0.05)$.

\section{Discussion}

Social constructions of gender, gender stereotypes, support systems and social influences, classroom environment, the instructor, and the competitive design of PE classes all have influences on each gender in PE class [17]. The purpose of this study was to examine single-sex classes versus coeducational classes in $7^{\text {th }}$ grade PE and the effect it had on PA level and perceived self-competence. A secondary purpose was to examine differences in PA levels between males and females in PE. There are many similarities as well as differences found between the current study and

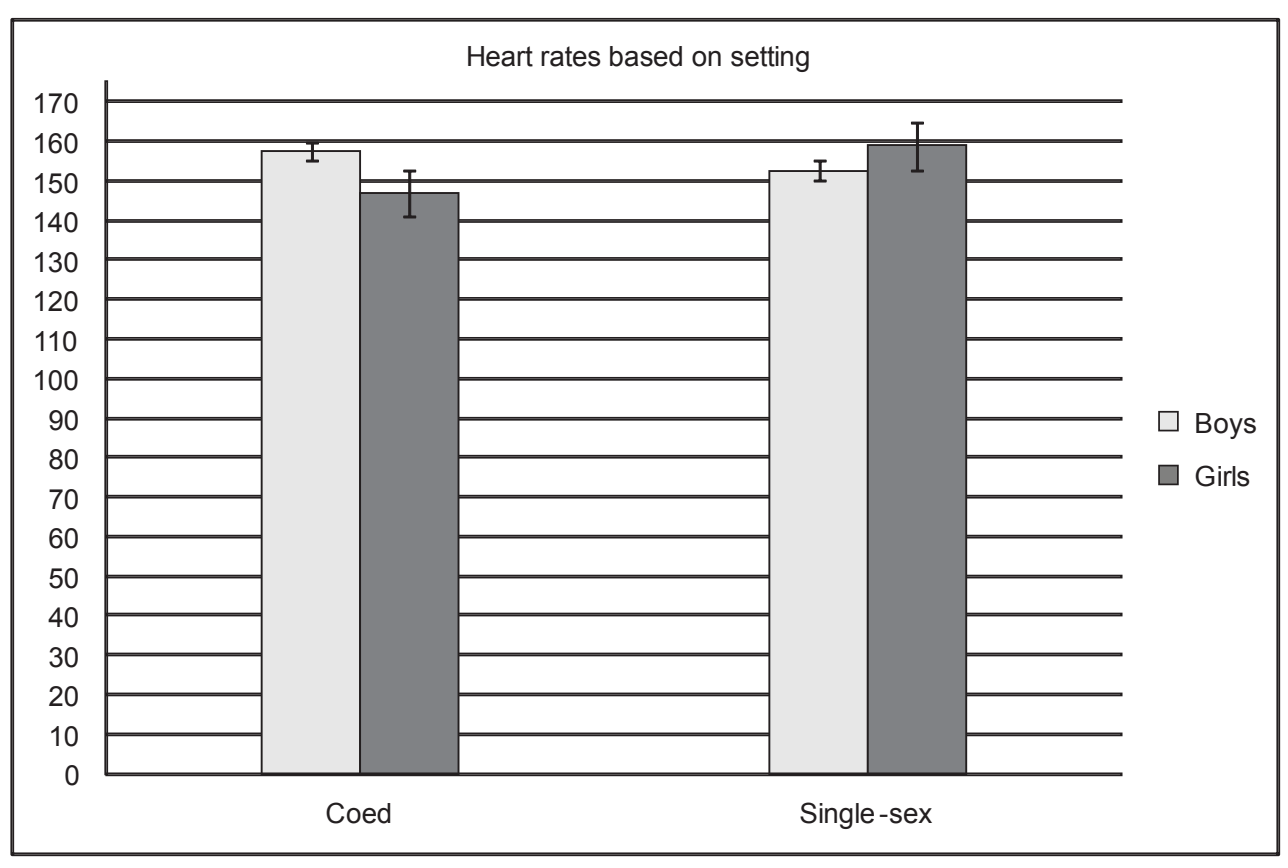

Figure 1. Mean differences of heart rate by sex and setting during gameplay 
others that have been done when comparing PA levels, PE setting preferences, and self-competence levels.

The results of the study were interesting, as they displayed results like a variety of completed studies, but also had some different outcomes compared with others. For instance, Turvey and Laws' [26] study had outcomes that displayed that males prefer the coeducational setting, which is different from what the current study has found. Additionally, Stidder [24] found that the male participants preferred single-sex classes. In the current study, males did not show a preferred setting in physical education. The number of males who preferred the single-sex physical education setting was similar to the number of males who preferred the coeducational setting. On the other hand, Osbourne et al. [19] demonstrated that students felt positively about the fact that they had the opportunity to interact with the opposite gender while in a coeducational class. This is similar to the findings of the current study, which displayed that students did not prefer one setting over the other.

The most significant relationship found in this study was that the females in the single-sex setting had higher average heart rates compared to females in the coeducational setting. The females in the single-sex setting had heart rates just as high as the males in the same setting, whereas females in the coeducational setting had heart rates that were significantly lower than the males. This relationship is similar to what was found in a study completed by Kulinna et al. [13]. That study took place in a coeducational setting with invasion games, very similar to the current study. In the study completed by Kulinna et al. [13], the male participants were especially active while the females had lower levels of physical activity. That study also showed that the males' physical activity levels in the coeducational setting were similar to those in the singlesex setting, which is comparable to the current study. In another study completed by Williams and Hannon, [28], junior high students' MVPA levels were examined using the tactical games model during a variety of units (basketball, soccer, flag football, and volleyball) in single-sex and coeducational settings. The results were consistent with the current study. The male students had similar levels of MVPA in both settings for every sports unit. The females in the study had higher levels of MVPA in the single-sex setting compared with the coeducational setting during the basketball unit.

One explanation for low MVPA among females in the coeducational setting, could be that females had fewer interactions with the basketball than they did in the singlesex setting. In a study conducted by Turvey and Laws [26], results revealed that males received contact with the ball more often than females did during gameplay in the coeducational setting. Males tended to pass to one another as opposed to passing to a female, even if a female was open during the game. Many females stated that the males did not pass to them in class because they did not think that they were "good" at the sport [26]. This could be a reason why there was a significant relationship between the PE setting and heart rates among the females in the single-sex setting as compared to females in the coeducational setting in the current study.

McKenzie et al. [16] examined the PA levels of females and males in both settings as well. Comparable to the current study, results indicated that the males had similar levels of PA in the coeducational setting as they did in the single-sex setting. However, unlike the current study, the females in the study completed by McKenzie et al. [16] had higher PA levels in the coeducational environment than in the single-sex setting. Hannon and Ratliffe [8] had similar findings after examining PA levels of males and females in each setting with the use of pedometers. Males and females in the study had an equal number or more steps per minute in the coeducational setting compared with single-sex setting. In another study, conducted in Europe, middle school students' levels of MVPA were examined with heart rate monitors and results revealed that the participants had higher MVPA levels in the coeducational setting as compared to the single-sex setting [27]. The inconsistencies noted in the results of studies comparable to the current study prove that more research needs to be completed in order to discover the best learning environment for students in PE classes.

The survey given to the participants in the current study was a modified version of the Confidence in Learning Mathematics scale, Math as a Male Domain scale, and Usefulness of Mathematics scale [6], where basketball was substituted for mathematics. There were three types of questions asked in the survey, which included confidence, usefulness, and gender-appropriateness. The students were given the survey one day before the basketball unit started and one day after it had ended. Results indicated that there were no significant relationships between the pre and post survey as well as the single-sex setting versus the coeducational setting. In other words, students in the single-sex setting felt just as confident, useful, and appropriate in the basketball unit as the students in the coeducational setting.

The survey given in the current study demonstrated that students' self-competence levels are similar to one another, regardless of the physical education setting. This statistical finding is different from those found in a study completed by Lyu and Gill [15]. In the previously mentioned study, female participants in single-sex classes had higher scores in perceived physical competence, satisfaction, and effort compared with female participants in coeducational classes. In the same study, females in the coeducational classes had extremely low perceived physical competence, low levels of satisfaction in PE, and displayed minimal effort. 
Deci and Ryan [4] found that perceived competence has a direct influence on motivation, which could essentially improve levels of MVPA. This statistic makes the findings of the current study interesting. There were no significant relationships between self-competence levels and PA levels, but the PA levels between the females in each setting were significantly different. Additional research needs to be completed on the relationship between self-competence levels and PA levels in the PE setting.

\section{Conclusions}

Overall, there are several studies that have shown similar results to the current study, but there are also studies that display variations to these findings. As previously mentioned, there are many recommendations for physical education teachers to use in order to provide quality education to students. Hill et al. [11] suggested giving the students a survey every year to determine which activities hold their interest. Suggestions for teachers in the coeducational setting included avoiding rules that are gender based and removing competition [7]. In a study done by Acker et al. [1], putting students into groups with fewer people for gameplay activities has also been proven to increase PA levels for students in PE. Since the current study did not show many significant relationships, more research should be done on the recommendations mentioned in various settings in order to provide the best methods of PE to promote lifelong learning. This study was limited to a small sample size from one school in the Midwestern part of the U.S. Additionally one sport (baseketball) was examined in this study. Future studies should include a larger sample size and examine various sports in relation to PE setting and self-competence.

\section{Conflict of interest: Authors state no conflict of interest.}

\section{References}

1. Acker R., Costa F., Bourdeaudhuij I., Cardon G., Haerens L. (2010) Sex equity and physical activity levels in coeducational physical education: Exploring the potential of modified game forms. Phys. Educ. Sport Pedagogy, 15(2): 159-173.

2. Cockburn C. (2001) Year 9 girls and physical education: A survey of pupil perceptions. The Bulletin of Physical Education, 37(1): 5-24.

3. DeAngelo L.P., Kalumuck K.P., Adlin E.M. (2015) Obesity. Magill'S Medical Guide (Online Edition).

4. Deci E., Ryan R. (2000) The "what" and "why" of goal pursuits: Human needs and the self-determination of behavior. Psychol. Inq., 11(4): 227-268.
5. Derry J., Phillips D. (2004) Comparisons of selected student and teacher variables in all-girls and coeducational physical education environments. Physical Educator, 61(1): 23-25.

6. Fennema E., Sherman J.A. (1976) Fennema-Sherman mathematics attitudes scales: Instruments designed to measure attitudes toward the learning of mathematics by females and males. JSAS Catalog of Selected Documents in Psychology, 6: 31.

7. Griffin P. (1985) Girls' and boys' participation styles in middle school physical education team sport classes: A description and practical applications. The Physical Educator, 42(1): 3-8.

8. Hannon J., Ratliffe T. (2005) Physical activity levels in coeducational and single-gender high school physical education settings. J. Teach. Phys. Educ., 24(2): 149-164.

9. Hannon J., Williams S. (2008) Should secondary physical education be coeducational or single-sex?, J. Phys. Educ. Recreat. Dance, 79(2): 6-56.

10. Heart Rate Training \& Technology| Heart Zones USA, (2015) Retrieved November 12, 2015, from http://www. heartzones.com/.

11. Hill G., Cleven B. (2005) A comparison of 9th grade male and female physical education activities preferences and support for coeducational groupings. Physical Educator, 62(4): 187-197.

12. Kahan D., McKenzie T.L. (2015) The potential and reality of physical education in controlling overweight and obesity. Am. J. Public Health, 105(4): 653.

13. Kulinna P., Martin J., Lai, Q., Kliber A., Reed B. (2003) Student physical activity patterns: Grade, gender, and activity influences. J. Teach. Phys. Educ., 298-310.

14. Lirgg C.D. (1993). Effects of same-sex versus coeducational physical education on the self-perceptions of middle and high school students. Res. Q. Exerc. Sport, 64: 324-334.

15. Lyu M., Gill D., (2011) Perceived physical competence enjoyment and effort in same-sex and coeducational physical education classes. Educational Psychology, 31(2): 247-260.

16. McKenzie T., Prochaska J., Sallis J., LaMaster K., (2004) Coeducational and single-sex physical education in middle schools: Impact on physical activity. Res. Q. Exerc. Sport, 75: 446-449.

17. Murphy B., Dionigi R.A., Litchfield C. (2014) Physical education and female participation: A case study of teachers' perspectives and strategies. Issues Educ. Res., 24(3): 241-259.

18. National Association for Sport and Physical Education. (2003). What constitutes a quality physical education program [Position statement]. Reston, VA: Author.

19. Osbourne K., Bauer A., Sutliff M. (2002) Middle school students' perceptions of coed versus non-coed physical education. Physical Educator, 59(2): 83-89. 
20. Pritchard T., McCollum S., Sundal J., Colquit G. (2014) Effect of the sport education tactical model on coeducational and single gender game performance. Physical Educator, 71(1): 132-154.

21. Rowe K. (1988) Single-sex and mixed-sex classes: The effects of class type on student achievement, confidence, and participation in mathematic. Aust. J. Educ., 32: 180-202.

22. Slingerland M., Haerens L., Cardon G., Borghouts L. (2014) Differences in perceived competence and physical activity levels during single-gender modified basketball game play in middle school physical education. Eur. Phys. Educ. Rev., 20(1): 20.

23. StataCorp. (2015) Stata Statistical Software: Release 14. College Station, TX: StataCorp LP.

24. Stidder G. (2000) Does Sex Matter? Pupil perceptions of physical education in mixed and single sex secondary schools. Br. J. Teach. Phys. Educ., 31(3): 40-44.

25. Title IX athletics. [electronic resource]: Accommodating interests and abilities: A briefing before the United States Commission on Civil Rights, Washington, DC. (2010). Washington, DC: U.S. Commission on Civil Rights, 2010 .
26. Turvey J., Laws C. (1988) Are girls losing out? The effects of mixed-sex grouping on girls' performance in physical education. Br. J. Phys. Educ., 19(6): 253-255.

27. Van Acker R., da Costa F.C., Bourdeaudhuij I.D., Cardon G., Haerens L. (2010) Sex equity and physical activity levels in coeducational physical education: exploring the potential of modified game forms. Phys. Educ. Sport Pedagogy, 15(2): 159-173.

28. Williams S.M., Hannon J.C. (2018) Physical Activity Levels in Coed and Same-Sex Physical Education Using the Tactical Games Model. The Physical Educator, 75(3): 525-545.

29. World Health Organization. (2021, March 8). Obesity and Overweight. https://www.who.int/news-room/factsheets/detail/obesity-and-overweight

\section{Received 20.10.2020 \\ Accepted 11.05.2021}

\section{(C) University of Physical Education, Warsaw, Poland}

